\title{
Resolution of Persistent Auditory Verbal Hallucinations after Long-term Electroconvulsive Therapy Maintenance: A Case Report of a Patient with Clozapine-resistant Schizophrenia
}

\author{
In Won Chung ${ }^{1,2}$, Hye Sung Kim ${ }^{1}$, Jung Hyun Kim ${ }^{1}$, Jin Hyeok Jang ${ }^{1}$, Yong Sik Kim ${ }^{2,3,4}$ \\ ${ }^{1}$ Department of Psychiatry, Dongguk University International Hospital, Goyang, ${ }^{2}$ Institute of Clinical Psychopharmacology, Dongguk University \\ College of Medicine, Goyang, ${ }^{3}$ Department of Neuropsychiatry, School of Medicine, Eulji University, Daejeon, ${ }^{4}$ Department of Psychiatry, \\ Nowon Eulji Medical Center, Eulji University, Seoul, Korea
}

\begin{abstract}
A 32-year-old woman with schizophrenia and persistent auditory verbal hallucinations (AVHs), which caused continuous suicidal thoughts and depression, was treated with electroconvulsive therapy (ECT) of an acute course followed by maintenance ECT (M-ECT) augmented onto clozapine for 7 years. Although the general psychopathology and AVHs initially reduced slightly with ECT and clozapine, her AVHs and suicidal thoughts did not decrease subjectively. When 3 years of M-ECT, her voices declined sharply, and improvement was maintained for 2 years thereafter. A total 91 ECT sessions were performed. The daily clozapine dose was decreased from 325 to $200 \mathrm{mg}$ and plasma levels remained higher than $350 \mathrm{ng} / \mathrm{ml}$; there were no noticeable cognitive side effects. In summary, we report a case showing a sudden sharp reduction in persistent AVHs after 3 years of long-term M-ECT.
\end{abstract}

KEY WORDS: Schizophrenia; Auditory verbal hallucinations; Clozapine; Maintenance electroconvulsive therapy.

\section{INTRODUCTION}

Auditory verbal hallucinations (AVHs) are the most common symptom of schizophrenia, occurring in $60-$ $80 \%$ of patients [1-3]. Although clozapine is highly effective in reducing AVHs and can be used on a long-term basis, more than $25 \%$ of patients treated with clozapine continue to suffer from $\mathrm{AVHs}$ [2,4-7]. Persistent AVHs are associated with an increased risk of suicide, violence, and hospitalization [8-10].

Electroconvulsive therapy (ECT) augmentation onto clozapine has been reported to be particularly effective for refractory schizophrenia [11-14]. However, the ECT effect on hallucinations per se has never been demonstrated, rendering its efficacy low $[7,15,16]$. Nonetheless,

Received: October 7, 2019 / Accepted: November 4, 2019 Address for correspondence: Yong Sik Kim Department of Neuropsychiatry, School of Medicine, Eulji University, Department of Psychiatry, Nowon Eulji Medical Center, Eulji University, 68 Hangeulbiseok-ro, Nowon-gu, Seoul 01830, Korea

E-mail: kys@snu.ac.kr

ORCID: https://orcid.org/0000-0002-8845-5186 there is no evidence that the therapeutic effect of ECT diminishes over time; rather, it appears to get stronger with continuing treatment $[17,18]$. Additionally, there is no evidence of persistent cognitive side effects associated with maintenance ECT (M-ECT) $[14,19,20]$, and several studies have actually shown improved cognition over time [13]. Well-designed studies of the long-term M-ECT effects on persistent $\mathrm{AVH}$ in patients with schizophrenia in terms of symptom resolution, persistence of any improvement, and relapse prevention are very limited $[13,17,21]$. Therefore, even case reports of very long-term ECT treatment could contribute to our understanding of the M-ECT effects on persistent AVHs [17].

We present the case of a female patient with schizophrenia who suffered from persistent $\mathrm{AVH}$ s associated with suicidal thoughts and depression despite long-term clozapine treatment. During 7 years of ECT and clozapine, persistent $\mathrm{AVH}$ s were eventually resolved and stabilized without significant cognitive side effects. This case report has been exempted from review by the Institutional Review Board, and written consent was provided by the patient.

(c) This is an Open-Access article distributed under the terms of the Creative Commons Attribution Non-Commercial License (http://creativecommons.org/licenses/by-nc/4.0) which permits unrestricted non-commercial use, distribution, and reproduction in any medium, provided the original work is properly cited. 


\section{CASE}

A 32-year-old unmarried woman, diagnosed with schizophrenia according to the Diagnostic and Statistical Manual of Mental Disorder-fourth and fifth editions (DSM-IV and V, respectively), reported persistent AVHs characterized by multiple voices and sexual content since her junior year of university at the age of 20 years. AVHs were heard almost all day and centered on accusations or intimidation by voices of men, women and even groups; these symptoms had interfered with her social activities for many years and led to several suicide attempts. She was hospitalized for recurrent psychotic symptoms, including severe AVHs, and started clozapine since 2008 after the failure of various antipsychotic medicines. In 2013, she transferred to our hospital with persistent AVHs and suicidal thoughts; her medications were clozapine $300 \mathrm{mg}$, aripiprazole $2 \mathrm{mg}$, escitalopram $10 \mathrm{mg}$, and clonazepam $0.5 \mathrm{mg}$. We attempted to increase the daily clozapine dose by more than $400 \mathrm{mg}$, but this failed because the plasma clozapine concentrations fluctuated and were frequently higher than $1,000 \mathrm{ng} / \mathrm{ml}$.

Augmentation of the clozapine treatment with ECT was recommended. After approval by the hospital's ECT Task Committee, acute course of ECT was performed 16 sessions in 46 days at the end of 2013. The electrical stimulus was delivered with a 1.0-ms brief pulse width and bilateral electrode placement by the upward titration method using a Spectrum 5000Q instrument (MECTA Corporation, Portland, OR, USA). Although she continued to experience AVHs after the acute ECT, she was relatively tolerant of clozapine $325 \mathrm{mg}$, diazepam $10 \mathrm{mg}$, and trihexyphenidyl $4 \mathrm{mg}$, and no further ECT was performed.

Eight months later in August 2014, she complained of escalating AVHs associated with increased irritability, depression, and suicidal thoughts. ECT was recommended again at irregular intervals, i.e., once every $1-3$ weeks because her overall psychopathology was not as severe as when ECT was initiated. Although her voices were not reduced to be able to continue her daily life, she became tolerable and went on receiving treatment. In the fall of 2017, her voices suddenly diminished, and she was able to recommence with social activities, including a close interpersonal relationship, shopping trips with her mother, and so on. Her medications were clozapine 200 mg, aripiprazole $2 \mathrm{mg}$, divalproex sodium $250 \mathrm{mg}$, and lor- azepam $1 \mathrm{mg}$ that were maintained for almost 2 years thereafter. Additionally, the inter-treatment intervals became to increase gradually to up to 6 weeks. The patient received 91 ECT sessions up to May of 2019, at energy levels of $80-384 \mathrm{mC}$; she has maintained $120 \mathrm{mC}$ of electricity since September 2017.

Total scores of Positive and Negative Syndrome Scale (PANSS), Hamilton Program for Schizophrenia Voices Questionnaire (HPSVQ) (Fig. 1) and Scale for Suicide Ideation (SSI) before starting ECT were 95 (positive syndrome: 22, negative syndrome: 24 , general psychopathology: 49), 34 (emotional factor: 16, physical factor: 18) and 18, respectively. These scores at the end of acute ECT were 80 (21, 18, and 41), 31 (15 and 16) and 9, respectively. In the fall of 2017 , when the patient experienced a sudden reduction in AVHs, the scores were 76 (15, 26, and 35), 17 (4 and 13) and 3, respectively. Scores

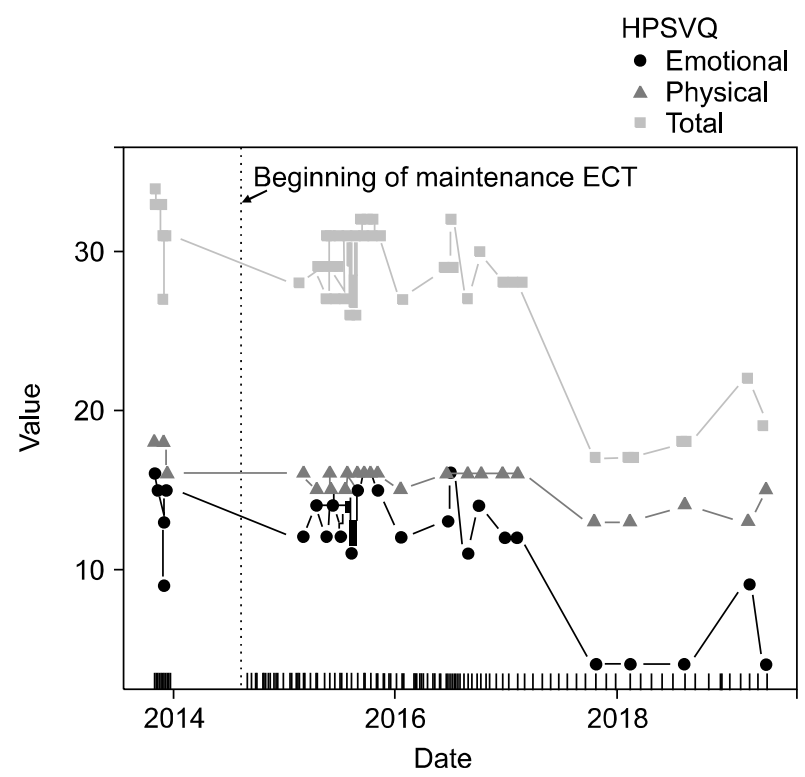

Fig. 1. Changes in Hamilton Program for Schizophrenia Voices Questionnaire (HPSVQ) scores during combined electroconvulsive therapy (ECT) and clozapine treatment of a patient with treatmentresistant schizophrenia The vertical lines at the bottom of the graph indicate the dates of ECT. The Kendall's tau ( $p$ value) for total, emotional factor, and physical factor HPSVQ scores was -0.310 (0.0242), -0.395 (0.0059), and $-0.130(0.404)$, respectively, when M-ECT data (after August of 2014) were analyzed. The total and positive syndrome, negative syndrome, and general psychopathology scores on the PANSS were $-0.0883(p=0.584),-0.317(p=$ $0.0510), 0.381(p=0.0190)$, and $-0.128(p=0.428)$, respectively. The $p$ value indicates the significance value whether Kendall's tau was zero or not.

M-ECT, maintenance ECT; PANSS, Positive and Negative Syndrome Scale. 
at the last observation, in May 2019, were 65 (16, 20, and 29), 19 (4 and 15) and 4, respectively.

Although systematic neurocognitive tests were not performed regularly, we did administer the Korean version of the Mini-Mental State Examination (MMSE-KC) and the Korean Version of the Montreal Cognitive Assessment (MoCA-K) at approximately 2-month intervals (mean interval, $65.2 \pm 58.4$ days). The MMSE-KC scores never fell below 28 points during acute ECT, and most of the MMSE-KC and MoCA-K scores were in the range of $27-$ 30 points during the M-ECT period; even when they temporarily dropped to $22-26$ points, they returned to the normal range in a few days.

\section{DISCUSSION}

The present patient noticed a sudden remarkable decrease in persistent $\mathrm{AVH}$ and suicidal thoughts when $M$-ECT and clozapine lasted for 3 years and was comfortable for the first time since her initial experience of AVHs. At the time she reported subjective improvement in $\mathrm{AVH}$, a clear decrease of $45.2 \%$ (from 31 to 17 ) in total HPSVQ score compared to when M-ECT was started, mainly due to the emotional factor, was noted in contrast to a $5.0 \%$ (from 80 to 76 ) decrease in the PANSS total score. Suicidal thoughts were also reduced by SSI. This improvement was subsequently maintained. Her daily clozapine dose was continued at $200 \mathrm{mg}$, but her clozapine plasma levels were never lower than $350 \mathrm{ng} / \mathrm{ml}$ during the observation period to rule out pseudo-resistance to clozapine. There were no noticeable cognitive side effects associated with M-ECT. It can be concluded that long-term ECT augmentation is effective for the resolution of the AVHs in this patient with insufficient response to clozapine $[7,19]$.

More specifically, the sharp reduction in AVHs was caused primarily by the suddenly remarkable decrease in the emotional factor score, from $11-16$ to 4 points. However, the monotonic decrease in total and emotional factor HPSVQ scores during M-ECT seemed not to be associated with PANSS scores, which gradually decreased during the observation period. This patient shows that long-term M-ECT may eventually lead to symptom reduction along with decreasing suicide thoughts even when the daily clozapine dose is gradually decreased to 200 mg. The sustained improvement with lower clozapine

doses therein suggests that decreased doses did not affect the therapeutic effect of M-ECT $[14,17,18]$.

One critical issue related to M-ECT concerns its potential to adversely affect cognitive function. However, it has been argued that evidence for worsening memory secondary to M-ECT is lacking [20]. Our previous study found that cognitive scale scores did not change over a 2-year observation period [14], and as mentioned above, a case report of 321 ECT sessions on a weekly base indicated no reduction in cognitive function [18]. It has been hypothesized that the reason that cognitive decline has not been observed in M-ECT relates to the increased inter-treatment intervals, which allow the brain sufficient time to recover [21,22]. Additionally, the use of bilateral electrode placement in single treatments separated by long intervals would not be expected to cause significant cognitive impairment [23]. Like previous researches [14], the present study did not detect any long-term decline in cognitive functioning during M-ECT, according to the MMSE-KC and MoCA-K.

In conclusion, this case demonstrates that AVHs may eventually improve, even in clozapine-resistant schizophrenia with persistent AHVs, when long-term M-ECT is continued. Further long-term follow-up studies including large numbers of patients may further elucidate the effectiveness of long-term M-ECT for persistent AVHs.

\section{Conflicts of Interest}

Dr. Kim YS received grants, research support and honoraria from Janssen, Otsuka, Hanmi, and Dainippon Sumitomo. Dr. Chung IW received research grants from Janssen, Otsuka, Hanmi, Whanin, Bukwang and educational grant from Mecta. Others have no conflicts of interest.

\section{Author Contributions}

Conceptualization: Yong Sik Kim. Data acquisition: Hye Sung Kim, Jung Hyun Kim, Jin Hyeok Jang. Formal analysis: In Won Chung, Yong Sik Kim. Funding: Yong Sik Kim. Supervision: Yong Sik Kim. Writing-original draft: In Won Chung, Yong Sik Kim. Writing-review \& editing: In Won Chung, Yong Sik Kim.

\section{ORCID}

In Won Chung

Hye Sung Kim

Jung Hyun Kim https://orcid.org/0000-0002-7852-7430

https://orcid.org/0000-0003-4297-9715

https://orcid.org/0000-0002-1804-2351 
Jin Hyeok Jang https://orcid.org/0000-0003-1471-5229

Yong Sik Kim https://orcid.org/0000-0002-8845-5186

\section{REFERENCES}

1. Shergill SS, Murray RM, McGuire PK. Auditory hallucinations: a review of psychological treatments. Schizophr Res 1998; 32:137-150.

2. Chung IW, Jeong SH, Jung HY, Youn T, Kim SH, Kim YS. Long-term changes in self-report auditory verbal hallucinations in patients with schizophrenia using clozapine. Psychiatry Investig 2019;16:403-406.

3. Kim SH, Hwang SS, Jung HY, Kim Y, Ahn YM, Chung IW, et al. Differences between self-reported and clinician-rated evaluations of 1-year changes in auditory verbal hallucinations among schizophrenia patients. Prog Neuropsychopharmacol Biol Psychiatry 2019;95:109671.

4. Meltzer HY. Treatment of the neuroleptic-nonresponsive schizophrenic patient. Schizophr Bull 1992;18:515-542.

5. González JC, Aguilar EJ, Berenguer V, Leal C, Sanjuan J. Persistent auditory hallucinations. Psychopathology 2006; 39:120-125.

6. Chang JS, Yi JS, Ahn YM, Kim JH, Kim YS. Stabilization of the internal structure of persistent auditory verbal hallucinations in schizophrenia. Aust N ZJ Psychiatry 2009;43:244-251.

7. Sommer IE, Slotema CW, Daskalakis ZJ, Derks EM, Blom JD, van der Gaag M. The treatment of hallucinations in schizophrenia spectrum disorders. Schizophr Bull 2012;38:704-714.

8. Hor K, Taylor M. Suicide and schizophrenia: a systematic review of rates and risk factors. J Psychopharmacol 2010;24(4 Suppl):81-90.

9. Gallagher AG, Dinan TG, Baker LV. The effects of varying information content and speaking aloud on auditory hallucinations. Br J Med Psychol 1995;68:143-155.

10. Honings S, Drukker $M$, Ten Have $M$, de Graaf $R$, van Dorsselaer S, van Os J. Psychotic experiences and risk of violence perpetration and arrest in the general population: a prospective study. PLoS One 2016;11:e0159023.

11. Petrides G, Malur C, Braga RJ, Bailine SH, Schooler NR, Malhotra AK, et al. Electroconvulsive therapy augmentation in clozapine-resistant schizophrenia: a prospective, randomized study. Am J Psychiatry 2015;172:52-58.
12. Kim HS, Kim SH, Lee NY, Youn T, Lee JH, Chung S, et al. Effectiveness of electroconvulsive therapy augmentation on clozapine-resistant schizophrenia. Psychiatry Investig 2017; 14:58-62.

13. Sanghani SN, Petrides G, Kellner CH. Electroconvulsive therapy (ECT) in schizophrenia: a review of recent literature. Curr Opin Psychiatry 2018;31:213-222.

14. Youn T, Jeong SH, Kim YS, Chung IW. Long-term clinical efficacy of maintenance electroconvulsive therapy in patients with treatment-resistant schizophrenia on clozapine. Psychiatry Res 2019;273:759-766.

15. Pandarakalam JP. Pharmacological and non-pharmacological interventions for persistent auditory hallucinations in schizophrenia. BJMP 2016;9:a914.

16. Dellazizzo L, Potvin S, Phraxayavong K, Lalonde P, Dumais A. Avatar therapy for persistent auditory verbal hallucinations in an ultra-resistant schizophrenia patient: a case report. Front Psychiatry 2018;9:131.

17. Kirov G, Creaby M, Khalid N, Atkins M. Four years of successful maintenance electroconvulsive therapy. J ECT 2009;25: 219-220.

18. Berg JE. Intractable schizo-affective disorder successfully treated with electroconvulsive treatment over six years. Ment IIIn 2012;4:e20.

19. Kim JH, Youn T, Choi JG, Jeong SH, Jung HY, Kim YS, et al. Combination of electroconvulsive therapy and clozapine in treatment-resistant schizophrenia. Psychiatry Investig 2018; 15:829-835.

20. Bailine SH, Sanghani SN, Petrides G. Maintenance electroconvulsive therapy is not acute electroconvulsive therapy. I ECT 2019;35:1-2.

21. Ward HB, Szabo ST, Rakesh G. Maintenance ECT in schizophrenia: a systematic review. Psychiatry Res 2018;264:131-142.

22. lancu I, Pick N, Seener-Lorsh O, Dannon P. Patients with schizophrenia or schizoaffective disorder who receive multiple electroconvulsive therapy sessions: characteristics, indications, and results. Neuropsychiatr Dis Treat 2015;11: 853-862.

23. Kellner $\mathrm{CH}$, Burns $\mathrm{CM}$, Bernstein $\mathrm{HJ}$, Monroe RR Jr. Electrode placement in maintenance electroconvulsive therapy. Convuls Ther 1991;7:61-62. 